\title{
A Comparative Electrochemical Study on Corrosion Inhibition of Iron by Synthesized Tetraphenyl Phosphonuim lodide in Acid Media
}

\author{
KHALED MANSOURI ${ }^{1}$, LAKHDAR SEKHRI ${ }^{1 *}$, \\ OUMELKHEIR RAHIM² and AHMED TABCHOUCHE ${ }^{1}$
}

'Lab. Dynamic Interactions and Reactivity of Systems, Process Engineering Department, Faculty of Applied Sciences, University Kasdi Merbah, Ouargla 30000, Algeria.

${ }^{2}$ Electrochemical Laboratory, Chemistry Department, Faculty of mathematics and Matter Sciences, University Kasdi Merbah, Ouargla 30000, Algeria.

${ }^{*}$ Corresponding author: E-mail: sekhril@yahoo.fr

http://dx.doi.org/10.13005/ojc/320428

(Received: July 17, 2016; Accepted: August 20, 2016)

\begin{abstract}
The present work is aimed mainly to synthesize a phosphonuim salt, tetraphenylphosphonuim iodide, and evaluate inhibitive effect against carbon steel corrosion in aerated $1 \mathrm{M} \mathrm{HCl}$ solutions. Thus, tetraphenylphosphonuim iodide was synthesized by the reaction of of an equimolar quantity of a solution of phenyl iodide and triphenyl phosphine in toluene ( $84 \%$ yield). We have found that, the use of toluene for this reaction of triphenyl phosphine with aryl or alkyl iodide is a convenient synthesis of many phosphonium salts since the halogen as a leaving group (requires a temperature higher than boiling point of chloroform. The purity of this compound was estimated by TLC technique and microanalysis, while its structure was supported by the usual spectroscopic methods such as UV, infrared, ${ }^{1} \mathrm{H}$. NMR and ${ }^{13} \mathrm{C}$. NMR. Exploration of the Corrosion measurements based on polarization resistance $(\mathrm{Rp})$, potentiodynamic polarization curves indicates that tetraphenylphosphonuim iodide, in most cases act as strong inhibitors. Tetraphenylphosphonuim iodide acts as anodic type inhibitors with predominant effect on the anodic dissolution of iron. Analysis of the polarization curves indicates that charge transfer process mainly controls carbon steel corrosion in $\mathrm{HCl}$ solution without and with phosphonuim salt. The mechanism of corrosion inhibition by phosphonuim; salt was discussed in the light of the molecular structure of the additive. A Comparative electrochemical study with that reported in the literature revealed that the efficiency of the inhibitors follows the order: tetraphenyl phosphonum iodide $>$ (chloromethyl) triphenyl phosphonium chloride (CTP) $>$ tetraphenyl phosphonum chloride $(T P)>$ triphenyl phosphine oxide (TPO) > triphenyl (phenylmethyl) phosphonium chloride (TPM).
\end{abstract}

Keywords: Iron; Phosphonium salt; Acid, corrosion, inhibition; potentiodynamic polarization. 


\section{INTRODUCTION}

Phosphonium salts have gained an increasing interest due to their successful applications in different fields of chemistry, such as the corrosion inhibitors. Thus, by definition, a corrosion inhibitor is a chemical substance that, when added in small concentration to an environment, effectively decreases the corrosion rate. To prevent the corrosion of the materials, organic compounds having o-bonds and heteroatoms such $\mathrm{O}, \mathrm{N}$ and $\mathrm{S}$ have been widely used. ${ }^{1-4}$ The inhibitive performances of a molecule are substantially connected on its adsorption on metal surface. In recent years, many experimental methods are used to determine the corrosion inhibition efficiencies and to understand the inhibition mechanisms of chemical compounds such as weight loss, ${ }^{5}$ potentiodynamic polarization (PDP), ${ }^{6}$ electrochemical impedance spectroscopy (EIS), ${ }^{7}$ Fourier transform infrared spectroscopy $(\mathrm{FTIR})^{8}$ and scanning electron microscopy $(\mathrm{SEM})^{9}$ in spite of the fact that they are in general expensive and time consuming too.

In recent years we have also published many papers about that phosphonium salts derivatives are effective against the corrosion of metals such as mild steel. ${ }^{10-11}$

Phosphonium salts appear to have a wide range of potential applications as corrosion inhibitors As is known, iron is one of the metals used widely used in industry and this metal may be exposed to corrosion due environmental factors. For this reason, the synthesis and design of new corrosion inhibitors to prevent the corrosion of iron are quite important.Thus, in this opportunity we

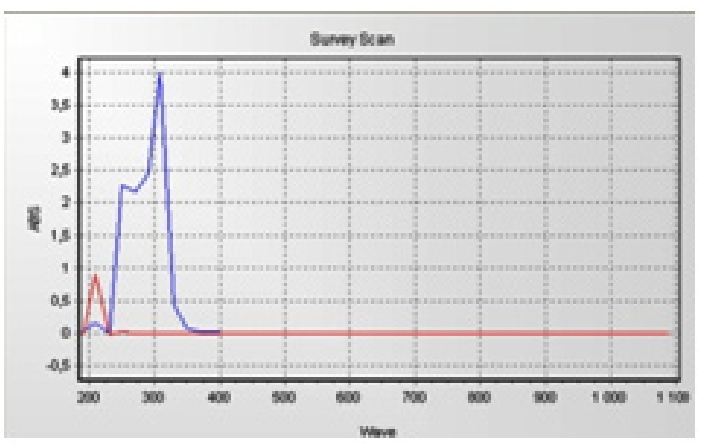

report here the synthesis and characterization of tetraphenylphosphonuim iodide acting as anodic type inhibitors with predominant effect.

\section{RESULTS AND DISCUSSION}

To support our development of electrochemical study for corrosion inhibition of iron by lists of numerous chemical compounds that exhibit inhibitive properties such as phosphonuim halide derivatives in acid media, we required a synthesis of different phosphonium salts such as tetraphenylphosphonuim iodide. Thus, the strategy we have adopted for this project consists of the following steps: (i) synthesis of tetraphenylphosphonuim iodide with taking considerations of cost, toxicity, availability, and environmental friendliness. (ii) Employing this product as a chemical inhibitor to decrease the rate of corrosion processes.

\section{Synthesis part \\ Experimental Materials}

Triphenylphosphine (98\%), iodobenzene (98\%), acetone (99.5\%), and hexane (99\%) were purchased from Alfa Aesar; magnesium sulfate anhydrous (97\%), and acetate ethyl was purchased from Acros Organics; Ethanol and toluene p.a were purchased from Biochem Chemopharma Co (Canada). All other reagents used were of analytical grade.

\section{Procedure for the Synthesis of tetraphenylphosphonuim iodide}

lodobenzene $(3.11 \mathrm{~g}, 15.26 \mathrm{mmol})$ was added in small portions to well-stirred solution of Triphenylphosphine $(4 \mathrm{~g}, 15.26 \mathrm{mmol})$ in toluene (20

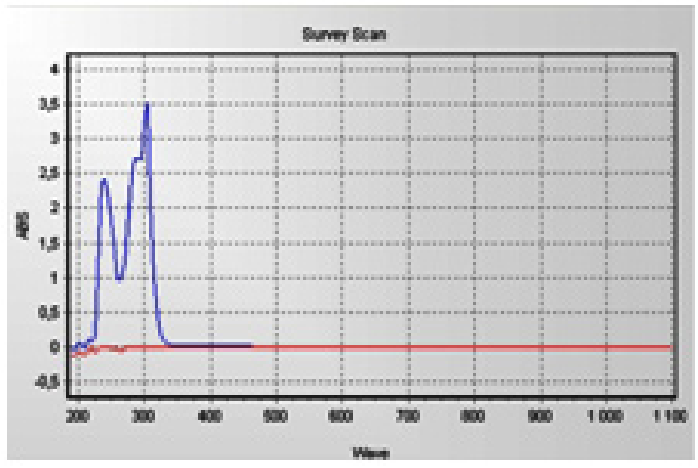

Fig.1: UV-vis (blancEtOH); UV-vis (blanc $\mathrm{CHCl}_{3}$ ) 
$\mathrm{mL})$. The resulting mixture was then heated under reflux for 1-1.5 hours. It was then allowed to cool to room temperature. The resulting precipitate was separated by filtration and the crude product was recrystallized from toluene to afford tetraphenylphosphonuim iodide $(5.98 \mathrm{~g}, 84 \%)$ as white crystals, m.p. $80^{\circ} \mathrm{C}$; $\lambda_{\text {max }}(\mathrm{KBr}$ disc $): 696.3,742.5,954.7,1068.5,1125$, 1434.9, 1558.4, 2341.4and $2350 \mathrm{~cm}^{-1}$; ${ }^{1} \mathrm{H}$ NMR: $\delta 7.3\left(\mathrm{~d}, 8 \mathrm{H}, \mathrm{J}=5.13 \mathrm{~Hz}\right.$, ortho $\left.\mathrm{P}^{+}-\mathrm{Ph}\right) ; 7.45$ (d, $12 \mathrm{H}, \mathrm{J}=1.83 \mathrm{~Hz}$, Meta and Para $\left.\mathrm{P}^{+-} \mathrm{Ph}\right)$; ${ }^{13} \mathrm{C}$ NMR: $\delta 117.9$ (-ve DEPT) $\left(4 \mathrm{C}, \mathrm{P}^{+}-\mathrm{Ph}\right) ; 130.4$ (8C, Meta $\left.\mathrm{P}^{+}-\mathrm{Ph}\right) ; 133.6\left(8 \mathrm{C}\right.$, ortho $\left.\mathrm{P}^{+}-\mathrm{Ph}\right) ; 135.0$ $\left(4 \mathrm{C}\right.$, Para $\left.\mathrm{P}^{+} \mathrm{Ph}\right) ; \lambda_{\text {max }}$ (blanc EtOH, $\mathrm{CHCl}_{3}$ ) $=300 \mathrm{nM}$ as shown in (Fig. 1)

\section{Methods}

All reactions were carried out under atmospheric air conditions. Solutions were dried over anhydrous magnesium sulphate $\mathrm{MgSO}_{4}$ and evaporated under reduced pressure using a rotary evaporator (rotary evaporator (IKA Evaporator RV
06-ML). Solvents were purified according to standard methods. ${ }^{12}$

\section{Physical measurements}

${ }^{1} \mathrm{H}$ NMR spectra were recorded on BRUCKER AC $300 \mathrm{MHz}$ spectrometer at $0^{\circ} \mathrm{C}$, and the chemical shifts are reported in $\mathrm{ppm}$ relative to the central line of the singlet for $\mathrm{CDCl}_{3}$ at $7.26 \mathrm{ppm}$. Coupling constants ( $\mathrm{J}$ values) are reported in hertz $(\mathrm{Hz})$, and spin multiplicities are indicated by the following symbols: s (singlet), d (doublet), t (triplet), q (quartet), m (multiplet).

${ }^{13} \mathrm{C}$ NMR and DEPT were recorded on BRUCKER AC $75 \mathrm{MHz}$ spectrometer at $0^{\circ} \mathrm{C}$ and all are reported in ppm relative to the central line of the triplet for $\mathrm{CDCl}_{3}$ at $77.16 \mathrm{ppm}$. The spectra reported are proton decoupled.

IR spectra were recorded on SHIMADZU 830-FTIR spectrometer using $\mathrm{KBr}$ pellets. Melting

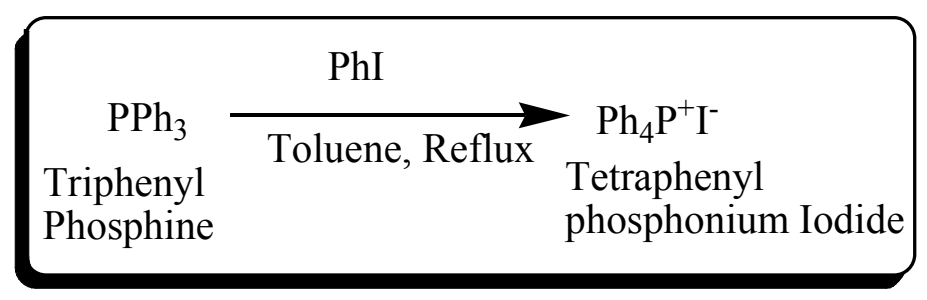

Scheme 1 : Synthesis of tetraphenylphosphonuim iodide

Table 1: chemical composition of carbon steel sheet

\begin{tabular}{llllllllllllllll}
\hline Element & $\mathbf{C}$ & $\mathbf{P}$ & $\mathbf{S}$ & $\mathbf{S i}$ & $\mathbf{M n}$ & $\mathbf{C r}$ & $\mathbf{N i}$ & $\mathbf{C u}$ & $\mathbf{A l}$ & $\mathrm{Nb}$ & $\mathbf{V}$ & $\mathrm{Ti}$ & $\mathrm{Mo}$ & $\mathrm{Fe}$ & \\
\hline Value $\left(\times 10^{-3}\right)$ & 65 & 2 & 1 & 245 & 1685 & 42 & 26 & 10 & 42 & 67 & 14 & 19 & 5 & Rest \\
\hline
\end{tabular}

Table 2: Electrochemical parameters for carbon steel in $1 \mathrm{M} \mathrm{HCl}$ solutions containing 10-70 ppm of tetraphenylphosphonuim iodide

\begin{tabular}{lccccccccc}
\hline $\begin{array}{l}\text { HCl 1M } \\
\text { (ppm) }\end{array}$ & $\begin{array}{c}\text { Rp } \\
\text { (ohm.cm2) }\end{array}$ & $\begin{array}{c}\text { IE\% } \\
(\mathbf{R p})\end{array}$ & $\begin{array}{c}\text { Ecorr } \\
(\mathbf{m V})\end{array}$ & $\begin{array}{c}\text { icorr } \\
(\mathbf{m A} / \mathbf{c m} 2)\end{array}$ & $\begin{array}{c}\text { IE\% } \\
\text { (icorr) }\end{array}$ & $\begin{array}{c}\text { Vcorr } \\
(\mathbf{m m} / \mathbf{a n})\end{array}$ & $\begin{array}{c}\mathrm{E} \% \\
\text { Vcorr }\end{array}$ & $\begin{array}{c}\beta_{\mathrm{a}} \\
(\mathbf{m V})\end{array}$ & $\begin{array}{c}\beta_{\mathrm{c}} \\
(\mathbf{m V})\end{array}$ \\
\hline 0 & 17.17 & - & -482.1 & 0.8861 & - & 10.36 & - & 80.0 & -89.1 \\
5 & 19.37 & 11.35 & -504.6 & 0.6533 & 26.27 & 7.640 & 26.25 & 65.3 & -82.1 \\
10 & 18.84 & 8.86 & -502.9 & 0.6962 & 21.34 & 8.142 & 21.40 & 64.3 & -85.2 \\
20 & 26.55 & 35.32 & -495.9 & 0.3649 & 58.81 & 4.267 & 58.81 & 52.4 & -64.6 \\
40 & 68.32 & 74.86 & -499.8 & 0.1968 & 77.79 & 2.302 & 77.77 & 61.4 & -87.0 \\
70 & 73.34 & 76.35 & -492.9 & 0.1198 & 86.48 & 1.401 & 86.64 & 45.9 & -60.2 \\
\hline
\end{tabular}


points were recorded on a Gallenkamp melting point apparatus, and are uncorrected.

Thin layer chromatography (TLC) was performed on precooked $0.25 \mathrm{~mm}$ silica gel plates 60F254 purchased from Merck.

\section{Interpretation}

We have published several papers describing the general route for the synthesis of aryl or alkyl triphenyl phosphonium halide such as methyl triphenyl phosphonium iodide by using triphenyl phosphine and aryl or alkyl halide in $\mathrm{CHCl}_{3} \cdot{ }^{10,11}$ The procedure was adopted for the synthesis of tetraphenyl phosphonium iodide except that toluene was used instead of chloroform as shown in scheme-1.

We have found that, the use of toluene for this reaction of triphenyl phosphine with aryl or alkyl iodide is a convenient synthesis of many phosphonium salts since the halogen as a leaving group (requires a temperature higher than boiling point of chloroform).

The general procedure involves dropwise addition of an equimolar quantity of a solution of phenyl iodide in toluene to a stirred solution of triphenyl phosphine in toluene at $0^{\circ} \mathrm{C}$. After the addition was complete, the reaction mixture was refluxed for 1-1.5 hours. Work-up of the reaction product gave the corresponding phosphonium salt, Tetraphenyl phosphonium iodide. Tetraphenyl phosphonium iodide was either commercially available or prepared from triphenyl phosphine and phenyl iodide as described earlier.

Tetraphenyl phosphonium iodide will be served as a chemical inhibitor to decrease the rate of corrosion processes. In the oil extraction and processing industries, inhibitors have always been considered to be the first line of defense against corrosion. A great number of scientific studies have been devoted to the subject of corrosion inhibitors. However, most of what is known has grown from trial and error experiments, both in the laboratories and in the field. Rules, equations, and theories to guide inhibitor development or use are very limited..$^{13}$ The scientific and technical corrosion literature has descriptions and lists of numerous chemical compounds that exhibit inhibitive properties. Of these, only very few are actually used in practice. The presence of iodide anion in the molecule of tetraphenyl phosphonium iodide increases the inhibition. ${ }^{14-17}$

The comparative study of this phosphonium, tetraphenyl phosphonium iodide with phosphonium chloride salts reported by K.F. Khaled revealed that this phosphonium salt is the convenient inhibitor. ${ }^{18}$

\section{Corrosion behaviour study Experimental details}

\section{Chemicals and solutions}

Working electrodes were cut from a carbon steel sheet, sample of the following chemical composition (as percentage):

This material (XC70) is utilised widely in petroleum and gas industry. Distilled and deionizer water was used for solution preparations. Stock solutions of $1 \mathrm{M} \mathrm{HCl}$ were employed as the blank, i.e., tetraphenylphosphonuim iodide-free. For the experiments containing tetraphenylphosphonuim iodide, the appropriate weight was added to blank solutions to reach final concentrations of $5,10,20$, 40 or $70 \mathrm{ppm}$.

\section{Cell, electrodes and coupons}

A double-walled glass three-electrode cell was used to carry out the corrosion tests. The working electrode was a disc of carbon steel with a geometric area of $1 \mathrm{~cm}^{2}$. Prior to each polarization experiment, the electrode surface was polished with 1200-4000 emery paper, degreased with acetone, rinsed with deionizer water and air-dried. The auxiliary electrode was a platinum rod and the reference electrode was a saturated calomel electrode (SCE) connected to the cell by a bridge. All potentials in the text are quoted versus this reference electrode.

\section{Apparatus}

Experiments were carried out under static conditions at $30^{\circ} \mathrm{C}$ on an potentiostat/galvanostat Applied research, potentiodynamic polarization curves were obtained using a PGZ301 potentiostat with Voltamaster 4 version 7.08 soft ware (radiometer analytical SAS). 


\section{Procedures}

The open-circuit potential (OCP) versus time and potentiodynamic polarization curves were measured for $0.5 \mathrm{~h}$. before starting the potentiodynamic polarization experiments. The initial potential sweep was always negative to the OCP previously measured. The initial and final potentials were fixed according to the technique employed (Tafel, polarization resistance, etc.).

\section{Open-circuit potential and corrosion potential}

The variation in the open-circuit potential (OCP) and the corrosion potential $\left(\mathrm{E}_{\text {corr }}\right)$ of the carbon steel electrode in $1 \mathrm{M} \mathrm{HCl}$ as a function of the tetraphenylphosphonuim iodide concentration is shown in Table 1.

The OCP values were obtained after 30 min immersion of the electrode in the test solutions under non-polarized conditions, while the $\mathrm{E}_{\text {corr }}$ values were determined by extrapolation of the Tafel lines, i.e., with the electrode polarized. Although the nature of the experiments is different, comparisons between the OCP and $\mathrm{E}_{\text {corr }}$ values are important to understanding the primary action of the corrosion inhibitor. The change in the OCP and $\mathrm{E}_{\text {corr }}$ values with

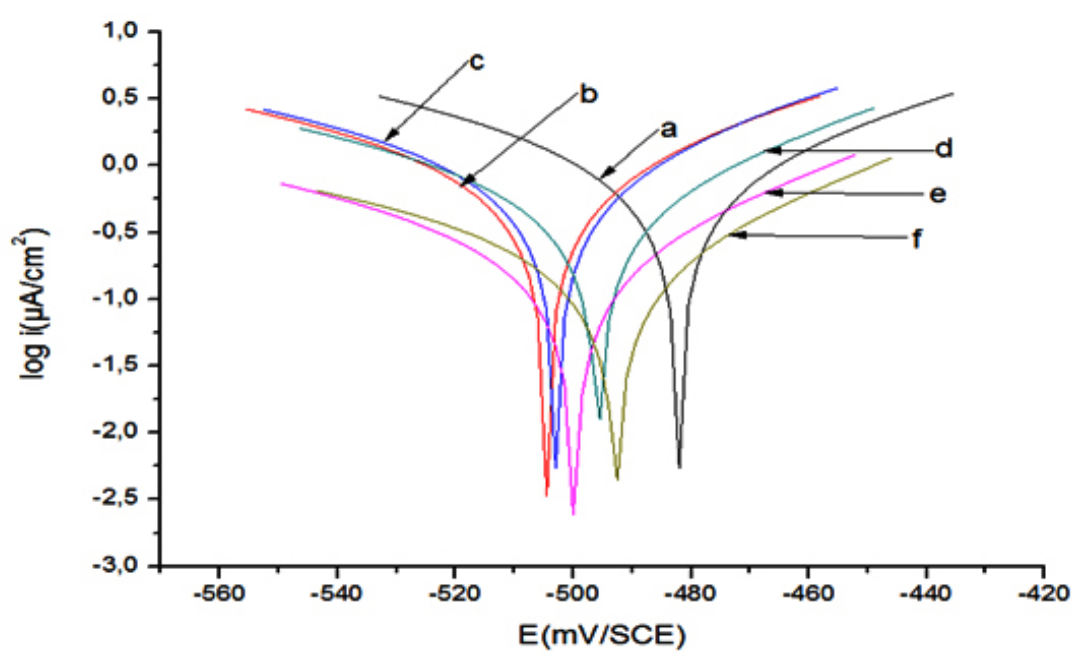

Fig. 2: Potentiodynamic polarization curves for carbon steel in $1 \mathrm{M} \mathrm{HCl}$ and solutions containing (a: 0 ppm), (b: 5 ppm), (c: 10 ppm), (d: 20 ppm), (e: 40 ppm) and (f: 70 ppm) of tetraphenylphosphonuim iodide

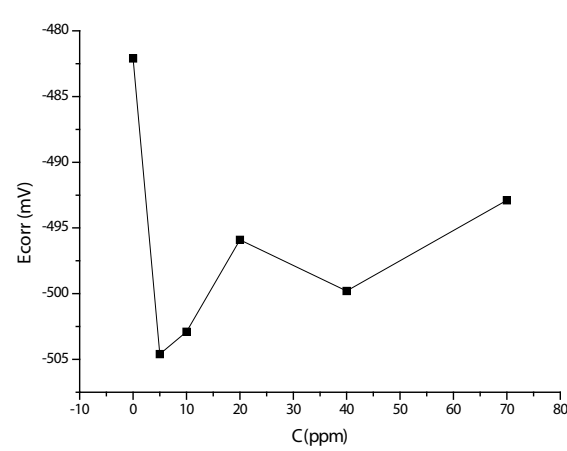

Fig. 3: Variation of the corrosion potential with the concentration of tetraphenylphosphonuim iodide in $1 \mathrm{M} \mathrm{HCl}$ solution

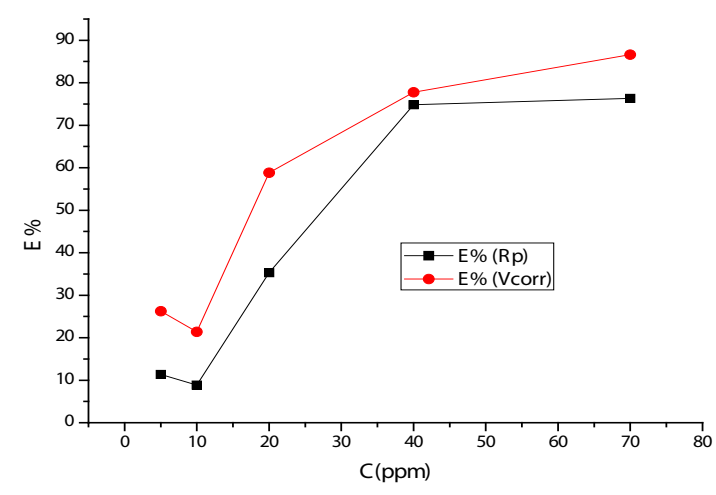

Fig. 4: Variation of the inhibition efficiency (as calculated from $R p$ and $V_{\text {corr }}$ results) with the concentration of tetraphenylphosphonuim iodide in $\mathrm{HCl} 1 \mathrm{M}$ solution 
the addition of the inhibitor is often a useful indication of which reaction is more affected: cathodic or anodic. The OCPs observed for carbon steel in $1 \mathrm{M}$ $\mathrm{HCl}$ solutions containing 5, 10, 20, 40 and 70 ppm

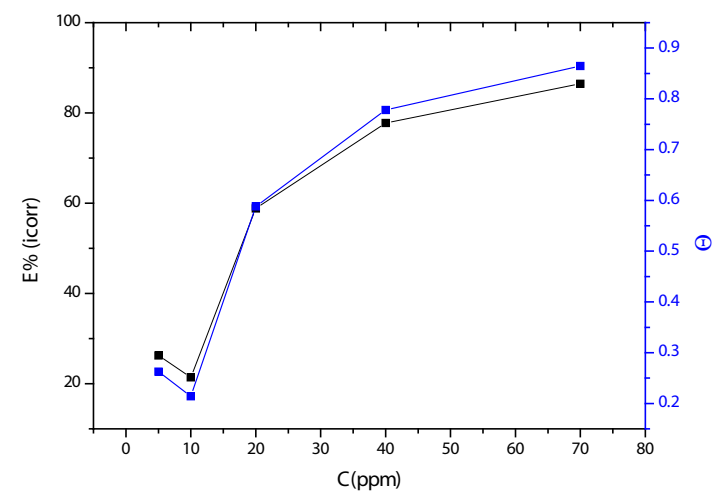

Fig. 5: Variation of the inhibition efficiency (as calculated from $i_{\text {corr }}$ and $\theta$ surface coverage results) with the concentration of tetraphenylphosphonuim iodide in $\mathrm{HCl} 1 \mathrm{M}$ solution

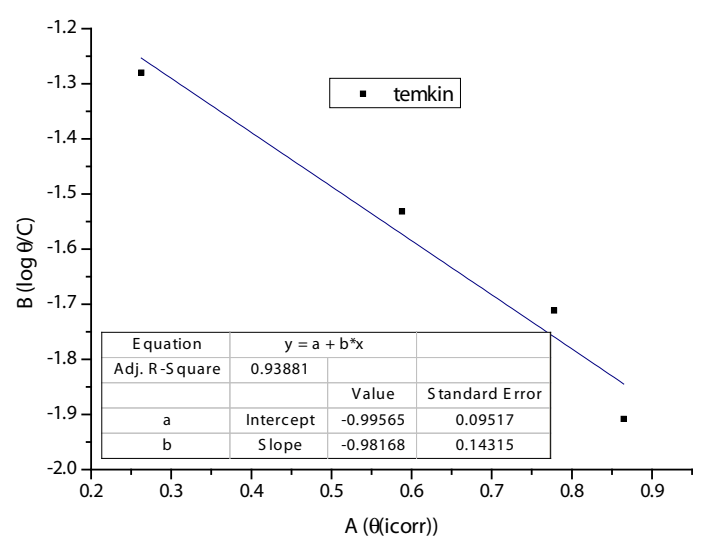

tetraphenylphosphonuim iodide were slightly more negative than that in the absence of the organic phosphonuim inhibitor.

On the other hand, $\mathrm{E}_{\text {corr }}$ was shifted by -20 $\mathrm{mV}$ towards more negative potentials under the same conditions. These results suggest that tetraphenylphosphonuim iodide can retard both reactions under open-circuit conditions: the oxidation of the oxide-free iron and the discharge of the hydrogen ions to produce hydrogen gas on the surface steel, since only a slight change in the OCP values was observed. However, when the working electrode is polarized, the data suggest that tetraphenylphosphonuim iodide acts preferentially on the cathodic sites, delaying the hydrogen evolution reaction, and the displacement of the $\mathrm{E}_{\text {corr }}$ was more well-defined. ${ }^{19}$

Adsorption is the mechanism generally accepted to explain the inhibitory action of organic corrosion inhibitors. ${ }^{20}$ Adsorption of inhibitors can affect the corrosion rate in two ways:

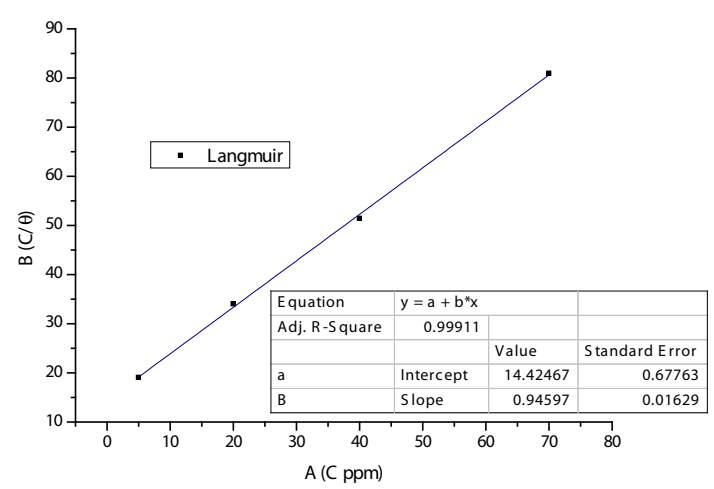

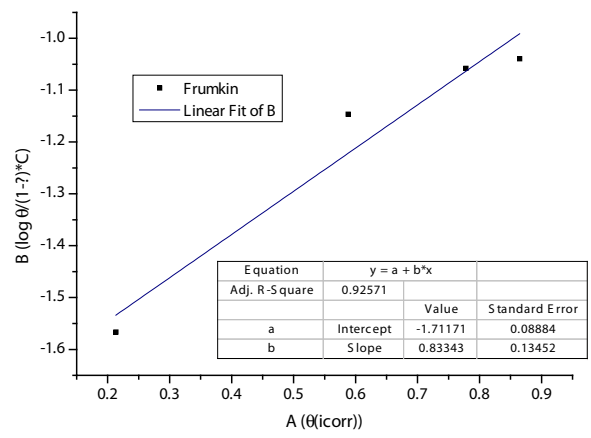

Fig. 6: Isotherms for the adsorption of tetraphenylphosphonuim iodide on the surface of carbon steel in $1 \mathrm{M} \mathrm{HCl}$ 
(i) By decreasing the available reaction area; the so-called geometric blocking effect; and (ii) by modifying the activation energy of the cathodic and/or anodic reactions occurring in the inhibitorfree metal in the course of the inhibited corrosion process. It is a difficult task to determine which aspects of the inhibiting effect are connected to the geometric blocking action and which are connected to the energy effect.

\section{Polarization measurements}

The kinetics of the anodic and cathodic reactions occurring on carbon steel electrodes in $1 \mathrm{M}$ $\mathrm{HCl}$ solutions with different tetraphenylphosphonuim iodide concentrations (5-70 ppm) was studied through the polarization measurements.

The complete potentiodynamic polarization curves are shown in Fig. 2. The electrochemical parameters, i.e. corrosion current density $\left(i_{\text {corr }}\right)$, anodic $\left(b_{a}\right)$ and cathodic $\left(b_{c}\right)$ Tafel constants and polarization resistance $\left(R_{p}\right)$, shown in Table 2, were collected from Tafe/ plots and polarization resistance experiments carried out separately.

Regarding the potentiodynamic polarization curves, as previously observed, it can be clearly seen that the $\mathrm{E}_{\text {corr }}$ values shifted to more negative potentials with an increase in the tetraphenylphosphonuim iodide concentration. This effect may be related to the adsorption of the organic phosphonuim compound at the active sites of the electrode surface, retarding the corrosion reaction. The increase in the tetraphenylphosphonuim iodide concentration caused a clear decrease in the cathodic current density, but did not change significantly the cathodic Tafel slopes (Table 2), indicating that the hydrogen evolution reaction is diminished exclusively by the surface blocking effect of tetraphenylphosphonuim iodide. ${ }^{20}$
Regarding the anodic region of the potentiodynamic polarization curves, there is no evidence of passive film formation on the electrode surface either in the presence or in the absence of the inhibitor. Also, the currents remained almost the same for the blank and the 5 and 70 ppm tetraphenyl phosphonuim iodide in the active dissolution region of the metal, but increased for higher concentrations of the organic phosphonuim compound. This behavior could be related to a change in the anodic reaction mechanism (iron dissolution), corroborated by a decrease in the anodic Tafel slope with increasing concentration of tetraphenylphosphonuim iodide (Fig.3).

This behavior could originate from the adsorption of the inhibitor at low concentrations. In addition to the energy effect, the pronounced lowering of the anodic Tafel slope could be partly due to electrochemical desorption of the inhibitor at higher concentrations from the metal surface during dissolution. ${ }^{21}$

Summarizing, the lowering of the anodic Tafel slope can be interpreted as being due to (i) the adsorption of tetraphenylphosphonuim iodide at lower concentrations (energy effect), (ii) a change in the mechanism reaction, and (iii) the desorption of tetraphenylphosphonuim iodide at higher concentrations, all in agreement with the mechanism proposed above.

The data shown in the Table 1 clearly show that the $i_{\text {corr }}$ values decreased and the $R_{p}$ values, as expected, increased in the presence of tetraphenylphosphonuim iodide, indicating that the corrosion process was suppressed with the increase in inhibitor concentration. The inhibition efficiency (IE\%) was computed for mild steel in $1 \mathrm{M}$ $\mathrm{HCl}$ solutions containing $5,10,20,40$ and $70 \mathrm{ppm}$ of tetraphenylphosphonuim iodide from the Tafel plots

Table 3: Isotherm adsorptions of tetraphenylphosphonuim iodide on the surface of carbon steel in $1 \mathrm{M} \mathrm{HCl}$

\begin{tabular}{lccccc}
\hline isotherme & Equation linear & $\mathbf{R}^{2}$ & $\mathbf{K}\left(\mathbf{M}^{-1}\right)$ & $\mathbf{g}$ or $\mathbf{a}$ & $\Delta \mathbf{G}_{\text {ads }}(\mathbf{k j} / \mathbf{m o l})$ \\
\hline Langmuir & $(\mathrm{C} / \theta)=0.946 \mathrm{C}+14.425$ & 0.999 & 32325.407 & 0.946 & -35.677 \\
Temkin & $\log (/ \mathrm{C})=-0.982-0.996$ & 0.939 & 1262458.56 & 0.982 & -44.757 \\
Frumkin & $\log (/(1-) \mathrm{C})=0.833-1.712$ & 0.926 & 2583282.966 & 0.833 & -46.531 \\
\hline
\end{tabular}


and polarization resistance measurements. The $\mathrm{R} \%$, $\mathrm{IE} \%$ values were obtained from $\mathrm{i}_{\text {corr }}$ and $\mathrm{R}_{\mathrm{p}}$ data using the equations below:

$$
\begin{aligned}
& \mathrm{R} \%=\left(1-\frac{\mathrm{v}_{\text {corr }}}{\mathrm{v}_{\text {corr }}^{0}}\right) * 100 \\
& \mathrm{IE} \%_{\text {icorr }}=\left(1-\frac{\mathrm{i}_{\text {corr }}}{\mathrm{i}_{\text {corr }}^{0}}\right) * 100 \\
& \mathrm{IE} \%_{\mathrm{Rp}}=\left(1-\frac{\mathrm{R}_{\mathrm{p}}^{0}}{\mathrm{R}_{\mathrm{p}}}\right) * 100
\end{aligned}
$$

Where $\mathrm{i}_{\text {corr }}^{0}$ and $\mathrm{R}_{\mathrm{p}}^{0}$ are the corrosion current density and the polarization resistance, respectively, measured in solutions without inhibitor and $\mathrm{i}_{\text {corr }}$ and $R_{p}$ are the same parameters determined in solutions containing inhibitor. The results obtained are given in Table1.

As can be seen, the IE\% increased with increasing concentration of tetraphenylphosphonuim iodide, but the IE\% values obtained from the Tafel experiments $\left(\mathrm{i}_{\text {corr }}\right)$ were higher than those obtained through the polarization resistance $\left(R_{p}\right)$. At a glance, this behavior suggests that the inhibitor action is dependent on the potential applied and time of polarization, since in the $R_{p}$ experiments only \pm 23 $\mathrm{mV}$ around $\mathrm{E}_{\text {corr }}$ was applied to the working electrode and the duration of the experiment was shorter. However, the data clearly show that the carbon steel electrochemical corrosion rate decreased in the presence of tetraphenylphosphonuim iodide. The phosphonuim salt was thus effectively adsorbed on the mild steel surface impeding the corrosion process supporting the mechanism discussed, which proposes that tetraphenylphosphonuim iodide acts by blocking the cathodic sites without a change in the mechanism of the hydrogen evolution reaction and by modifying the activation energy of the anodic reaction occurring in the inhibitor-free metal in the course of the inhibited corrosion process.

\section{Adsorption isotherms}

In order to evaluate the adsorption process of tetraphenylphosphonuim iodide on the carbon steel surface, Langmuir, Temkin and Frumkin adsorption isotherms were obtained according to the following equations. ${ }^{22-24}$
Langmuir: ${ }^{\theta} /(1-\theta)=\mathrm{KC}$

Rearrangement gives

$$
(C / \theta)=1 /{ }_{K}-a C
$$

Temkin:

$$
\log (\theta / C)=\log \mathrm{K}-\mathrm{g} \theta
$$

Frumkin:

$$
\theta /(1-\theta) \exp (-g \theta)=\mathrm{KC}
$$

or it s linear forme:

$$
\log (\theta /(1-\theta) \mathrm{C})=\log \mathrm{K}+\mathrm{g} \theta
$$

Where ${ }^{\boldsymbol{\theta}}$ is the surface coverage, $\mathrm{K}$ the adsorption-desorption equilibrium constant, $\mathrm{C}$ the inhibitor concentration and $\mathrm{g}$ the adsorbate interaction parameter. Considering that the doublelayer capacitance is proportional to the surface not covered by the inhibitor, the fraction of the surface covered by adsorbed molecules was determined according to the ratio. ${ }^{25}$

$$
\theta_{\text {icorr }}=\left(1-\frac{i_{\text {corr }}}{i_{\text {corr }}^{0}}\right)=\frac{E \%\left(i_{\text {corr }}\right)}{100}
$$

Where $\mathrm{i}_{\text {corr }}$ and $\mathrm{i}_{\text {corr }}^{0}$ are the corrosion current densities in the presence and absence of the inhibitor, respectively

The increasing steel surface coverage as a function of tetraphenylphosphonuim iodide concentration is shown in Fig. 6. To determine which adsorption isotherm best fits the surface coverage and to calculate the free-energy of adsorption, the respective plots were obtained. The three isotherms tested fitted well the data obtained, as can be

The constant $\mathrm{K}$ is related to the standard free energy of adsorption $\left(\Delta \mathrm{G}_{\mathrm{ads}}\right)$ by the equation:

$$
K=(1 / 55.5) \exp \left(-\Delta G^{0} / R T\right)
$$

Values of the constant $\mathrm{K}$ and the standard free energy of Adsorption by different isotherms for 
tetraphenyl phosphonuim iodide molecules in the table 3.

Where $\mathrm{K}$ is the equilibrium constant of the adsorption process. Fig. 6. shows plot of $\mathrm{C} / \boldsymbol{\theta}$ against $\mathrm{C}$ where straight lines are obtained. For the inhibitor, the slope of the straight line is equal to unity while the straight line obtained in case of tetraphenylphosphonuim iodide has a slope $>1$. So, it could be concluded that Phosphonuim salt is adsorbed at the steel surface following Langmuir isotherm without interaction between the adsorbed molecules. In case of tetraphenylphosphonuim iodide, deviation of the slope from unity can be explained in terms of repulsion or attraction of the adsorbed molecules adjacent to each other, a fact which was ignored during the derivation of Langmuir isotherm. The interaction between tetraphenylphosphonuim iodide molecules can be ascribed to the steric hindrance exerted by the tetra phenyl groups.

Adsorption of tetraphenylphosphonuim iodide molecules was found to obey Frumkin's model which is given by linear equation $(\log (/(1-)$ $C)=0.833-1.712$ ) and Fig. 5 where $g$ is the parameter of interaction between molecules adsorbed on the metal surface. The characteristic parameters of adsorption of tetraphenylphosphonuim iodide were found to obey Temkin's isotherm: $\mathbf{g}=-0.982$, $\mathrm{K}=0.996$. The negative value of $\mathrm{g}$ indicates the presence of repulsive forces between the adsorbed species of tetraphenylphosphonuim iodide. For tetraphenylphosphonuim iodide, values of $\mathrm{K}$ and $\Delta \mathrm{G}_{\text {ads }}$ by different isotherm were found to be [32325.407, 1262458.56 and 2583282.966] $\mathrm{M}^{-1}$ and $[-35.677,-44.757$ and -46.531$] \mathrm{kJ} \mathrm{mol}^{-1}$ while the high negative value of $\Delta \mathrm{G}_{\mathrm{ads}}$ indicates that tetraphenylphosphonuim iodide is strongly adsorbed (chemisorptions) on the steel surface.

These results are analogous to those reported by K.F. Khaled which involves inhibiting action of (chloromethyl) triphenyl phosphonium chloride (CTP), tetraphenyl phosphonum chloride (TP), triphenyl phosphine oxide (TPO), triphenyl (phenylmethyl) phosphonium chloride (TPM) and triphenyl phosphine (TPP) on the corrosion of iron in $1 \mathrm{M} \mathrm{HCl}$ solution using potentiodynamic polarization and electrochemical impedance spectroscopy
(EIS). ${ }^{18}$ Moreover, the experimental results provides further evidence that CTP, TP, TPO, and TPM act as inhibitors for iron in acid environments, while TPP is an accelerator. These compounds are mixedtype inhibitors and the inhibition efficiency is due to the presence of chloride ion which increased with increasing concentrations. By comparison our results with those obtained by Khaled, tetraphenyl phosphonium iodide derivative show good cathodic inhibition performance.

A Comparative electrochemical study with that reported in the literature revealed that the efficiency of the inhibitors follows the order: tetraphenyl phosphonum iodide $>$ (chloromethyl) triphenyl phosphonium chloride (CTP) $>$ tetraphenyl phosphonum chloride (TP) > triphenyl phosphine oxide (TPO) > triphenyl (phenylmethyl) phosphonium chloride (TPM). It was also reported in the literature ${ }^{26-}$ ${ }^{30}$ that the efficiency of halide inhibitors follows the order: $\mathrm{I}^{-}>\mathrm{Br}^{r}>\mathrm{Cl}^{-}>\mathrm{F}^{-}$.

\section{CONCLUSION}

Tetraphenyl phosphonum iodide has been successfully synthesized in high yield. Exploration of electrochemical studies showed that the results obtained from tetraphenylphosphonuim iodide are a excellent corrosion inhibitor for carbon steel under acidic conditions. The maximum inhibition efficiency was $\mathbf{8 6 . 4 8} \%$ for 70 ppm. Excellent agreement between the inhibition efficiencies calculated using polarization techniques was obtained.

The adsorption of the phosphonuim salt inhibitor onto the carbon steel surface was characterized by the decrease in (i) the cathodic and anodic current densities observed in the potentiodynamic polarization curves carried out in the presence of tetraphenylphosphonuim iodide.

The organic phosphonuim molecule acts by blocking the cathodic surface sites and by modifying the activation energy of the anodic reaction. The former effect was demonstrated by the decrease in the cathodic current densities observed in the potentiodynamic polarization curves without changes in the respective Tafel slope, while the later was observed through the changes in the Tafel slopes of the anodic polarization curves. 
The chimisorption aspect of the adsorption process was well-established by the value of $\ddot{A}^{0}{ }^{0}$ $=[-35.677,-44.757$ and -46.531$] \mathrm{kJ} \mathrm{mol}^{-1}$ calculated from the slope of the Langmuir, Temkin and Frumkin isotherms which best fitted the experimental data of the relationship between tetraphenylphosphonuim iodide concentration and surface coverage; $R^{2}=0.999$, 0.939 and 0.926 . The lower activation energy of the corrosion process in the presence of the corrosion inhibitor, when compared to that in its absence, also demonstrated the chemisorptive nature of the adsorption.

\section{ACKNOWLEDGMENT}

The authors wish to express their sincere thanks to Algerian Ministry of Higher Education and Scientific Research (MHESR) for their support and providing the necessary facilities to carry out this research. Sincere thanks are due to Dr. Ali Lounes, the Dean of the faculty of mathematics and Matter sciences, Kasdi Merbah-Ouargla University, Algeria for his assistance and providing a laboratory for carrying out this research.

\section{REFERENCES}

1. Obot, I.B.; Macdonald, D.D.; Gasem, Z.M. Corros. Sci. 2015, 99, 1-30.

2. Leçe, H.D. ; Emregül, K.C.; Atakol, O. Corros. Sci. 2008, 50, 1460-1468.

3. Raicheva, S.N. ; Aleksiev, B.V. ; Sokolova, E.I. Corros. Sci. 1993,34, 343-350.

4. Kaya, S.; Tuzun, B.; Kaya, C.; Obot, I.B. J. Taiwan Inst. Chem. Eng. 2016, 58, 528535.

5. Amin, M.A. Electrochim Acta. 2007, 52, 3588-3600.

6. Holland, R.I. Dent. Mater. 1992, 8 (4) 241245.

7. Duarte, R.G.; Castela, A.S.; Neves, R.; Freire, L.; Montemor, M.F. Electrochim. Acta. 2014, 124, 218-224.

8. Musiæ, S.; Gotiæ, M.; Popoviæ, S.; J. Mater. Sci. 1993, 28, 5744-5752.

9. Walocha, J.A.; Litwin, J.A.; Miodoñski, A.J. Hum. Reprod. 2003, 18, 1088-1093.

10. Sekhri, S; Lawrence, N.J. J. Soc.Alger Chim. 1999, 9 (1) 33-38.

11. Sekhri, S; Lawrence, N.J. J. Soc.Alger Chim. 1999, 10 (1) 9-21.

12. Perrin, D.D.; Armarego, W.L.F.; Purification of Laboratory Chemicals, Pergamon Press: New York, 1988.

13. Pierre, R. Roberge Handbook of Corrosion Engineering, New York, 2000

14. Quraishi, M.A.; Rawat, J.; Ajmal, M. Brit. Corros. J. 1999, 34, 220-229.

15. Feng, Y.; Siow, K.S.; Teo, W.K.; Hsieh, A.K.; Corros. Sci. 1999, 41, 826-836.

16. Syad Azim, S.; Muralidharan, S.;
Venkatakrishna Iyer, S.; Muralidharan, B.; Vasudevan, T. Brit. Corros. J. 1998, 33, 297306.

17. Bentiss, F; Bouanis, M.; Mernari, B.;Traisnel, M.; Lagrenée, M. J. Appl. Electrochem. 2002, 32, 671-683.

18. Khaled, K.F. An electrochemical study for corrosion inhibition of iron by some organic phosphonium chloride derivatives in acid media; Applied Surface Science. 2004, 230 , 307-318.

19. Roberge, P.R.; Corrosion inhibitors, in: Handbook of Corrosion Engineering, McGrawHill, New York, 1999,. 833-862.

20. Martinez, S.; Metikos-Hucovic, M. A nonlinear kinetic model introduced for the corrosion inhibitive properties of some organic inhibitors, J. App. Electrochem. 2003, 33, 1137-1142.

21. Drazic, D.M.; Vracar, L.; Drazic, V.J.; The kinetics of inhibitor adsorption on iron, Electrochim. Acta. 1994, 39, 1165-1170.

22. Morad, M.S. J. Appl. Electrochem.1999, 29, 619-626.

23. El-Awady, A.A.; Abd-El-Nabey, B.A.; Aziz, S.G. J. Electrochem. Soc. 1992, 139, 2149 2154.

24. Ashassi-Sorkabi, H.; Gahlebsaz-Jeddi, N.; Hashemzadeh, F.; Jahani, H. Electrochim. Acta. 2006, 51, 3848-3854.

25. Gyorik, G.L.; Mészros, G.; Lengyel, B.; Lendvay, G. Electrochemical and quantum chemical studies on the formation of protective films by alkynols on iron, Corr. Sci. 2003, 45, 1685-1702. 
26. Obot, I. B. Synergistic Effect of Nizoral and lodide Ions on the Corrosion Inhibition of Mild Steel in Sulphuric Acid Solution, J. Portugaliae Electrochimica Acta. 2009, 27(5), 539-553.

27. begum, A.; Harikrshna, S.; Irfanulla, K.; Veena, K. Enhancement of the Inhibitor Efficiency of Atropine Methochloride in Corrosion Control of Mild Steel in Sulphuric Acid ; $E$-Journal of Chemistry, 2008, 5 (4), 774-781.
28. Sadaf, K.; Quraishi, M.A. Synergetic Effect of Potassium lodide on Inhibitive, Performance of Science and Engineering, 2010, 35, 7182.

29. Umoren, S. A.; Solomon, M. M.; Udosoro, I. I.; Udoh, A. P. Synergetic and antagonistic effects between halide ions and carboxymethyl cellulose for the corrosion inhibition of mild steel in sulphuric acid solution ; Cellulose, 2010, 17, 635-648. 